\title{
European Healthy Hydration Awareness Campaign for Dietitians
}

\author{
Katerina Belogianni ${ }^{\mathrm{a}} \quad$ Joan Gandy ${ }^{\mathrm{b}}$ Annemieke van Ginkel ${ }^{\mathrm{a}} \quad$ Judith Liddell ${ }^{\mathrm{a}}$ \\ Roselyne Y. Wagner ${ }^{c}$ Laura Lagoudakis ${ }^{c}$ Pauline Douglas ${ }^{\mathrm{a}, \mathrm{d}}$ \\ ${ }^{a}$ European Federation of the Associations of Dietitians; ${ }^{b}$ Nutrition and Dietetics, School of Life and Medical \\ Sciences, University of Hertfordshire, Hatfield, UK; ${ }^{C}$ Hydration and Health Department, Danone Research, Palaiseau, \\ France; ${ }^{\mathrm{d}}$ Nutrition Innovation Centre for Food and Health, Ulster University, Coleraine, UK
}

\section{Keywords}

Water · Hydration - Dietitians · Knowledge .

Practice $\cdot$ Education

\begin{abstract}
Up to $50 \%$ of the adult population fail to meet the recommended total water intake despite the adverse health outcomes associated with chronic low fluid intake. Total fluid intake plays an important role in the energy and nutrient intake of individuals. Dietitians' role is to advise and guide the population toward a healthier diet. However, based on existing evidence, dietitians' current knowledge and practices regarding healthy hydration is an area for improvement. The European Healthy Hydration Awareness Campaign (EuHHAC) is an initiative between the European Federation of the Associations of Dietitians (EFAD) and the Hydration and Health Department of Danone Research, which aims to increase knowledge and awareness of healthy
\end{abstract}

hydration and provide dietitians with evidence-based resources to use in practice. Since 2016, a series of tasks were undertaken by the EuHHAC group targeting dietitians across Europe. These tasks included an online survey addressing gaps in hydration knowledge, a webinar providing information on the terminology and impact of hydration on health, an interactive session addressing facilitators and barriers to healthy hydration, and a tutorial summarizing key hydration information and take-home messages. Dietitians were actively engaged in each aspect. Based on the feedback received, awareness of hydration was increased among dietitians. To further enhance understanding, an online Hydration Resource Center, including the resources of EuHHAC, will be created and uploaded on the EFAD website. Once completed an evaluation study will be undertaken to assess the usefulness of the resources in practice. The deliverables will be cascaded across Europe and worldwide via social media, conferences, and publications. @ 2019 The Author(s)

Published by S. Karger AG, Basel

\begin{tabular}{|c|c|c|}
\hline KARGER & $\begin{array}{l}\text { (ङ) } 2019 \text { The Author(s) } \\
\text { Published by S. Karger AG, Basel }\end{array}$ & $\begin{array}{l}\text { Karger } \\
\text { Open access }\end{array}$ \\
\hline $\begin{array}{l}\text { E-Mail karger@karger.com } \\
\text { www.karger.com/anm }\end{array}$ & $\begin{array}{l}\text { This article is licensed under the Creat } \\
\text { NonCommercial-NoDerivatives } 4.0 \text { Int } \\
\text { NC-ND) (http://www.karger.com/Se } \\
\text { Usage and distribution for commercial } \\
\text { tribution of modified material requires }\end{array}$ & $\begin{array}{l}\text { Commons Attribution- } \\
\text { ational License (CC BY- } \\
\text { es/OpenAccessLicense). } \\
\text { tposes as well as any dis- } \\
\text { tten permission. }\end{array}$ \\
\hline
\end{tabular}

Pauline Douglas

Nutrition Innovation Centre for Food and Health

Ulster University, Coleraine Campus, Cromore Road

Coleraine, Co Londonderry, BT52 1SA (UK)

E-Mail pl.douglas@ulster.ac.uk 


\section{Introduction}

Water is a core component of the human body, it represents on average $60 \%$ of the body weight of adult men and $50-55 \%$ of adult women $[1,2]$. Maintaining fluid balance is therefore critical for optimal functioning of the human body. The European Food Safety Authority (EFSA) recommends a daily total water intake (TWI) for adult males of $2.5 \mathrm{~L}$ and for adult females $2.0 \mathrm{~L}$, with specific recommendations for children, adolescents, pregnant, and lactating women [2]. Evidence from large crosssectional surveys conducted across Europe, Asia, and South America found that only $39 \%$ of children, $25 \%$ of adolescents, and $51 \%$ of adults met the EFSA guidelines for adequate intake of water from fluids [3]. Chronic low fluid intake has been associated with an increased incidence of diseases of the urinary system, including urolithiasis, urinary tract infection, chronic kidney disease (CKD), bladder cancer [4], and kidney stones [5]. In healthy adults, it has been shown that individuals habitually consuming low fluid volumes had an increased urine osmolality, urine specific gravity, and solute concentrations [6]. There are many methods to assess hydration status in individuals (e.g., body mass change, urine osmolality, salivary osmolality) with their validity depending on variables such as individual lifestyle characteristics (e.g., exercise level) or whether the measurement is taken under controlled environmental factors (e.g., laboratory) or in the field [7]. Twenty-four hour urine osmolality was found to be strongly correlated with total fluid intake (TFI) among healthy sedentary adults in free-living conditions [6]. Water homeostasis is maintained by the action of the arginine vasopressin hormone on the kidney. High levels of copeptin, a surrogate marker of arginine vasopressin, have been associated with an increased risk of type 2 diabetes [8], metabolic syndrome [9], CKD, and cardiovascular risk in both people with diabetes and the general population $[10,11]$. High levels of copeptin are also associated with the development of CKD and CKD progression in the general population [12]. Recently, it has been shown that increasing water intake in low-volume drinkers reduces copeptin levels in healthy adults $[13,14]$ and decreases by $48 \%$ the recurrence of urinary tract infections [15]. Also, increasing water intake seems to benefit individuals of all stages of CKD or at risk of CKD [16].

The term TWI has been used in studies to include the sum of water from fluids and food [17]. Fluids included all kind of beverages (milk, juices, coffee, tea, soft drinks) and plain water [17]. Fluids and foods both contribute to
TWI of individuals. Liquid foods (soups, broths), yogurt, and some vegetables contain $80-99 \%$ water, while even solid or dried foods such as butter and raisins contain some amount (10-19\%) of water [1]. Data from nutrition surveys in the United Kingdom and France found that water from fluids contributed 59 to $76 \%$ of TWI, and water from food contributed 24.7 to $41 \%$ of TWI in the different age-groups of the populations [18]. Fluids and food are also an integral part of diet due to their nutrient and energy content. In particular, data from large population surveys in Spain, Mexico, and the United States revealed that mean energy intakes from foods and beverages ranged from 1,816 to 2,437 kcal with fluids contributing $12 \%$ (in Spain) to $21.7 \%$ (in Mexico) of total energy intake [19]. Dietitians are particularly concerned about the increased intakes of sugar-sweetened beverages (SSB) due to their detrimental consequences on oral health and body weight in children [20] and adults [21]. The World Health Organization suggests that intake of added sugars should not exceed $10 \%$ of daily total caloric intake, with additional benefits occurring if intakes are limited to $5 \%$ [22]. Evidence from large cross-sectional surveys across Europe found that juices and SSB contributed $35-45 \%$ of TFI in children and adolescents and $15-20 \%$ in adults [3]. In the United States, data from the national survey showed that SSB intake contributed 6\% of total caloric intake [19]. Drinking water instead of SSB is recommended by health organizations, as water is free of calories [1], while an increased water intake has been associated with higher diet quality [23]. Moreover, SSB consumption has been shown to be positively associated with and has an impact on body weight measured in children [24]. Water-based interventions in children have been associated with weight loss, mainly due to the substitution of caloric beverages with water intake, particularly in children who were overweight or obese at baseline [25].

Assessing TFI is challenging, with evidence showing that the most common methods used in research are single or multiple 24-h recalls, food diaries, or food frequency questionnaires validated against specific nutrients or energy intake [17]. Dietitians sometimes underestimate drinking behavior (alcohol, plain water) outside of meal times as they are mainly interested in assessing nutrient and energy intake from food and fluids [26]. Seven-day records were found to be more reliable in capturing fluid intake when compared with 24 -h recalls in an adult population [27]; for example, a 2017 study by Johnson et al. [28] validated a 7-day fluid record against body water turnover in healthy adults. However, the use of fluid records might be less appropriate for assessing TFI in other
58

Ann Nutr Metab 2019;74(suppl 3):57-65 DOI: $10.1159 / 000500347$
Belogianni/Gandy/van Ginkel/Liddell/ Wagner/Lagoudakis/Douglas 


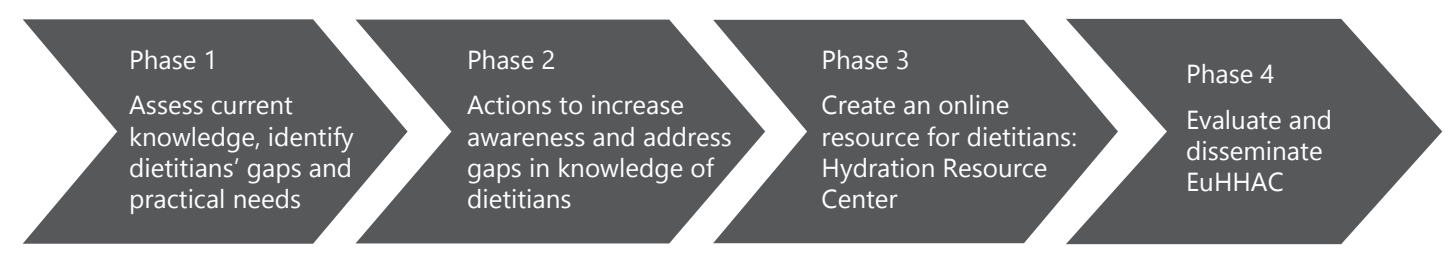

Fig. 1. EuHHAC project phases and key components (the roadmap). EuHHAC, European Healthy Hydration Awareness Campaign.

age-groups such as children and adolescents or older people. According to the review by Warren et al. [29], the use of repeated 24-h recall is a very suitable method for assessing TFI in adolescents, but less appropriate for children aged 5-8 years. Similarly, Jimoh et al. [30] found that the use of a self-reported Drinks Diary in older people with cognitive capacity to complete it, assessed more accurately their daily TFI when compared to the intake recorded on fluid charts by staff (direct observation of TFI was used as the reference method in this study). When assessing TFI, it is also important to consider factors that might lead to poor documentation, such as lack of staff or time in a busy ward [31] or the use of online instead of paper tools, which have been found to facilitate recording [32]. As a result, using the most appropriate method to assess TFI depends on the targeted population, whether TFI is assessed as part of dietary intake or it is the primary objective, and the availability of time and resources to undertake the assessment.

Individuals should aim to reduce the intake of added sugars from foods and fluids, drink water instead of sugary and alcoholic drinks, and reach the recommended fluid intake for their age and gender [2]. To achieve that, dietitians should have a sound knowledge of the role of water in human body, the different types of fluids and their impact on health, the recommended fluid intakes for each group of people, and use valid tools to assess TFI and hydration status of individuals. Findings from a cross-sectional study among dietitians in the United Kingdom suggest that half or less of respondents were aware of the dietary reference values of fluid and water for adults as well as the water content of foods and drinks [33]. In addition, although most dietitians considered themselves as responsible for managing hydration in patients, during a practical session, $24 \%$ of them did not mention anything about hydration and $33 \%$ spent $<10$ min talking about hydration with patients [33]. Only $18 \%$ of dietitians answered that they "always" assess patients' hydration status and the majority perceived as "very important" that dietitians should receive education on hydration. These find- ings highlight the importance of increasing awareness on healthy hydration among dietitians, clarify any misconceptions, and provide evidence-based tools to use in practice.

In an effort to address the above objectives, the European Federation of the Associations of Dietitians (EFAD) in collaboration with experts on healthy hydration from Danone Research developed the European Healthy Hydration Awareness Campaign (EuHHAC). This joint initiative aims to promote healthy hydration in the current food "climate" expressed in the World Health Organization European Food and Nutrition Action Plan 2015-2020 [34] and complemented in the EFAD European Dietetic Action Plan [35]. Primary objectives of the current project are to address gaps in the current knowledge of dietitians regarding healthy hydration, to undertake actions to increase awareness of healthy hydration, and to provide evidence-based resources for dietitians to use in their daily practice. Secondary EuHHAC objectives include evaluation of the project and communication of its outputs internationally, to encourage hydration science research and engage policy makers to adjust/apply fluid intake recommendations in their country. The EuHHAC project plan, showing the key components of each phase, is outlined in Figure 1. The project was launched in 2017 and will be completed in 2019. The following paragraphs describe in chronological order the actions that have been taken and the lessons learned from each experience ( $\mathrm{Ta}$ ble 1).

\section{Actions Taken to Date}

\section{Identifying Gaps in Hydration Knowledge}

Initially, a questionnaire based on the knowledge, attitude, and practice model [36] was developed by the working group of EuHHAC, to assess gaps in the hydration knowledge among dietitians in Europe. The questionnaire was disseminated through 10 European Spe- 
Table 1. Actions taken as part of the EuHHAC project

\begin{tabular}{|c|c|c|c|c|c|c|}
\hline Actions & Year & Duration & Participants & Aim & Brief description of content & Main outcomes \\
\hline $\begin{array}{l}\text { Online } \\
\text { survey }\end{array}$ & 2016 & 3 months & 102 dietitians & $\begin{array}{l}\text { To assess gaps in hydration } \\
\text { knowledge }\end{array}$ & $\begin{array}{l}\text { A questionnaire based on the } \\
\text { KAP model ( } n=\text { number of } \\
\text { questions): } \\
\text { - Water balance/EFSA } \\
\text { recommendations for } \\
\text { age-groups/total water intake }(n=6) \\
\text { - Country-based recommendations } \\
\text { of fluid intake }(n=4) \\
\text { - Definition/sugar content of } \\
\text { beverages }(n=2) \\
\text { - Definition/signs of } \\
\text { dehydration }(n=3) \\
\text { - Practical hydration } \\
\text { advice }(n=4)\end{array}$ & $\begin{array}{l}\text { Inadequate knowledge was found for } \\
\text { recommended intakes of fluid and } \\
\text { water, terminology of fluids, regulatory } \\
\text { mechanisms of water and sugar content } \\
\text { of fizzy drinks }\end{array}$ \\
\hline Webinar & 2017 & $1 \mathrm{~h}$ & $\begin{array}{l}98 \text { dietitians attended } \\
\text { online ( } 514 \text { views to date) }\end{array}$ & $\begin{array}{l}\text { To increase awareness and } \\
\text { provide evidence about } \\
\text { healthy hydration and } \\
\text { prevention of chronic } \\
\text { diseases }\end{array}$ & $\begin{array}{l}\text { The webinar was developed on the } \\
\text { basis of online survey results. } \\
\text { Content included: } \\
\text { - Functions of water in body } \\
\text { - Factors affecting hydration } \\
\text { requirements } \\
\text { - Recommended water intake } \\
\text { - Epidemiological data of } \\
\text { fluid intake } \\
\text { - Hydration and health (kidney } \\
\text { diseases, obesity) } \\
\text { - Use of copeptin as a predictor } \\
\text { for disease risk }\end{array}$ & $\begin{array}{l}90 \% \text { of attendees rated themselves as } \\
\text { satisfied or very satisfied with the webinar. } \\
\text { FAQs were posed about water intake and } \\
\text { kidney diseases, country-based } \\
\text { recommendations, and water content in } \\
\text { foods. FAQs were answered, and } \\
\text { responses were sent to attendees together } \\
\text { with resources }\end{array}$ \\
\hline $\begin{array}{l}\text { Interactive } \\
\text { session }\end{array}$ & 2018 & $1 \mathrm{~h}$ & $\begin{array}{l}\sim 100 \text { dietetic or nutrition } \\
\text { students }\end{array}$ & $\begin{array}{l}\text { To increase awareness and } \\
\text { provide practical tools and } \\
\text { tips about hydration and } \\
\text { fluid intake }\end{array}$ & $\begin{array}{l}\text { The lecture included: } \\
\text { - Terminology of fluids } \\
\text { - Recommended fluid intakes } \\
\text { - Methods for assessing } \\
\text { hydration status } \\
\text { - Tips about water and fluid intake } \\
\text { - Use of intravenous fluids in } \\
\text { dehydrated older people. } \\
\text { Interactive activities included } \\
\text { (dietitians were asked to): } \\
\text { - Estimate their total fluid intake } \\
\text { and energy content of fluids via } \\
\text { 24-h recall } \\
\text { - Guess the volume (mL) of } \\
\text { water contained in different } \\
\text { shapes of glasses } \\
\text { - Record perceived barriers and } \\
\text { facilitators of fluid intake in } \\
\text { older people living in care homes }\end{array}$ & $\begin{array}{l}\text { Dietitians were efficient in using a } 24 \text {-h } \\
\text { recall to assess fluid intake but found it } \\
\text { difficult to guess the amount of water } \\
\text { contained in glasses of different shapes. } \\
\text { Attendees also addressed potential } \\
\text { barriers and facilitators of fluid intake in } \\
\text { older people living in care homes and } \\
\text { methods to increase water intake in } \\
\text { community settings (Table 2) }\end{array}$ \\
\hline $\begin{array}{l}\text { Tutorial on } \\
\text { Hydration }\end{array}$ & 2018 & 2 days & $\begin{array}{l}\text { Delegates of the 40th EFAD } \\
\text { conference }\end{array}$ & $\begin{array}{l}\text { To summarize key messages } \\
\text { about hydration and } \\
\text { communicate the launch } \\
\text { of EuHHAC }\end{array}$ & $\begin{array}{l}\text { A short ( } 4 \text { min) video tutorial } \\
\text { presenting: } \\
\text { - Water balance and losses } \\
\text { in the body } \\
\text { - An overview of the current } \\
\text { EFSA recommendations } \\
\text { - Definitions and classifications } \\
\text { of fluids } \\
\text { - Demonstration of country-based } \\
\text { fluid recommendations for adults } \\
\text { - Definition and symptoms of } \\
\text { dehydration } \\
\text { - Take-home messages. } \\
\text { The video was displayed on } \\
\text { monitors near a booth located in } \\
\text { the conference exhibition area }\end{array}$ & $\begin{array}{l}\text { Many delegates stopped to watch the } \\
\text { video and take notes. A quiz was given to } \\
\text { challenge their knowledge. Hydration } \\
\text { experts were available to inform delegates } \\
\text { about the scope and progress of the } \\
\text { EuHHAC project and discuss any queries. } \\
\text { Educational materials (e.g., EFSA } \\
\text { recommendations leaflets, urine color } \\
\text { chart) were provided to delegates }\end{array}$ \\
\hline
\end{tabular}

EuHHAC, European Healthy Hydration Awareness Campaign; EFSA, European Food Safety Authority; KAP, knowledge, attitude and practice. 
cialist Dietetic Networks of EFAD and all EFAD delegates during the summer of 2016. The EuHHAC group received 102 responses from a range of European countries. The survey found that $50 \%$ of respondents did not know the current EFSA TWI recommendations for adults and $49 \%$ were not aware that older people have similar requirements to adults. About half of respondents (45\%) didn't know that a child's thermoregulatory mechanisms are not fully developed. There was confusion over the definitions of TWI and TFI with $31 \%$ of respondents unable to distinguish that TWI is the sum of water from fluids and food. There was great variation in defining the term "beverage". More than $50 \%$ of respondents had inadequate knowledge about the average sugar content of a fizzy drink. Finally, when asked about their country's water recommendations, $58 \%$ did not provide an answer.

\section{Hydration Webinar}

Based on the findings of the survey, dietetic experts of the EuHHAC group developed a hydration webinar, which was presented using the EFAD platform and supported by the European Network of Dietetic Students. The webinar consisted of 2 parts. The first covered the water content and its functions in the body, factors affecting hydration needs, recommended daily TWIs, epidemiological data regarding fluid intake, evidence relating hydration to health (kidney diseases, obesity), and the use of copeptin as a predictor for disease risk. The second webinar section presented the results of the questionnaire investigating the hydration awareness of dietitians. Over 400 people submitted applications to attend the webinar. Unfortunately, the system could only accommodate 100 attendees. As a result, 98 people across Europe watched the webinar of which 70 provided feedback through a follow-up online survey. Attendees were mainly dietitians and students in nutrition or/and dietetics. The feedback was positive, with $90 \%$ of attendees rating themselves as satisfied or very satisfied with the webinar. Queries were posed with regard to water intake and its impact on CKD, acute kidney disease, and stage $3 \mathrm{CKD}$. Attendees said it would be useful to receive further information about foods with a high water content. They also asked if it would be possible to pictorially or visually present the water intake of European countries. Also, participants viewed evidence-based information about the health benefits of water intake as useful tools for dietitians to inform patients. Those resources were sent to those who attended, and frequently asked questions were answered. The EuHHAC webinar (Water:
The Forgotten Nutrient) can be viewed on the YouTube channel; it had been viewed over 550 times at the time of this publication.

\section{Interactive Session}

Following the feedback received from the attendees of the webinar, a registered dietitian and hydration expert of the EuHHAC group developed a session during the preconference Academy of the 10th Hydration for Health Scientific Conference in Evian, France, in 2018. Approximately 100 dietetic and nutrition students attended the session that lasted for $1 \mathrm{~h}$ and included both didactic lecturing and interactive learning. The content of the presentation included terminology, fluid recommendations, intake of SSB, assessment methods of hydration status and drinking behavior, practical advice to increase water intake, information about the use of intravenous fluids in dehydration, and optimal hydration in older people. The activities focused on the estimation of TFI and energy content via $24-\mathrm{h}$ recall, as well as the visual presentation of the same volume of water using different shapes of glasses. Additionally, the attendees were asked to (a) suggest potential barriers to and facilitators of fluid intake in older people living in care homes and (b) suggest ideas to create a water-friendly environment and encourage people to drink water in community settings.

Twenty-seven attendees provided answers about barriers, 26 about facilitators, and 23 suggested ideas on promoting water intake in community settings. Regarding dietitians' perceptions about barriers, 2 main themes emerged. Theme 1 included barriers in relation to older people's physical dysfunction related to aging (e.g., incontinence, poor memory), dietary factors that might prevent fluid intake (e.g., prescribed low intake of salt), and individual attitudes/behavior (e.g., low awareness, tiredness). Theme 2 included barriers related to care home resources and facilities. Examples included the lack of staff or lack of staff time to perform tasks related to fluid intake, negative attitudes/behavior of staff such as unwillingness to assist older people to visit the bathroom and environmental barriers (e.g., lack of access to fluids). Regarding dietitians' perceptions of facilitators, 2 main themes emerged. Theme 1 included facilitators that related to older people's characteristics including the contribution of those who take care of older people (care givers), as well as attitudes, behavior, and social interactions with others. Theme 2 included facilitators that included resources/facilities of care homes (e.g., staff with positive attitudes and behaviors toward fluid intake), the resources of care homes (e.g., well-informed staff, pro- 
viding special cups/beakers/water bottles), and having a water-friendly environment (e.g., fluids are accessible in rooms and with meals). Regarding dietitian responses about encouraging people to increase their water intake in community settings, they reported giving tips and advice to individuals, acting as role models; they also suggested that community and policy makers could create social campaigns and provide easy access to safe water and toilets in public places. These themes and examples of responses of dietitians are summarized and presented in Table 2.

\section{Hydration Tutorial}

A hydration tutorial was designed for delegates attending the 40th EFAD conference in Rotterdam on September $28-29,2018$. The tutorial was a 4 -minute video displaying, graphically and in text, information about water balance and water losses in the human body, an overview of the current EFSA water intake recommendations for various age-groups, definitions, and classifications of fluid types; a map depicting the fluid recommendations of various countries worldwide; the definition and symptoms of clinical dehydration; and "take-home" messages. The video played in a loop on a monitor displayed at a booth in the conference exhibition area. Leaflets with EFSA recommendations and urine color charts for assessing hydration status were also available. Two hydration experts supported this booth. These activities informed delegates about the launch and aims of the $\mathrm{EuH}$ HAC project, answered queries about hydration, distributed hydration leaflets, and answered delegate questions. By the end of the conference, the hydration experts concluded that many delegates were aware of the EuHHAC project and inquired when the outputs of the project would be available online. In particular, delegates were interested in methods of assessing hydration status, water intake of specific demographic groups (e.g., older people, children), and the impact of hydration and dehydration intake on health. They also mentioned that online resources such as webinars and YouTube videos are the preferred modes of learning and increasing awareness about hydration among dietitians.

\section{Summary and Conclusions}

The EuHHAC is a joint initiative of EFAD and the Hydration and Health Department of Danone Research, which attempts to increase awareness and provide evidence-based resources for dietitians to promote healthy hydration. Completed actions include an online survey to assess current gaps in hydration knowledge, a webinar to clarify the recommended intakes of fluids, an interactive session to provide tips and advice, collecting dietitian views and opinions about hydration topics, and an online tutorial to graphically present key messages.

The project is currently in Phase 3 (Fig. 1), presenting resources via the EFAD online Healthy Hydration Resources Center for members of EFAD (i.e., including clinicians, students, researchers, and academics). Subscribers will be able to access the resources at any time and download printed materials for use in their dietetic practice (e.g., fluid intake data of various countries, tools to assess fluid intake, and recommendations for different groups).

Based on experiences and feedback, the EuHHAC group acknowledges that dietitians were very keen to learn more about hydration, in particular for groups of people with varying needs or requirements. Also, they expressed interest in accessing user-friendly and validated tools to promote healthy fluid intake and assess TFI or hydration status of people in community and clinical settings. After completing Phase 3, the EuHHAC group will undertake a pilot study to test the feasibility of the newly created hydration resource center and creates focus groups among dietitians across Europe to evaluate the impact of the project and necessary future activities. Once completed, EuHHAC and its deliverables will be cascaded across Europe and worldwide via social media, conferences, and published outputs.

Several education programs for dietitians exist; some are fully based on mentoring [37] or e-learning [38]. The unique features of EuHHAC reside in the specificity of hydration science as its topic, the various modes of delivery, and its iterative building process.

Hydration science is an underappreciated topic in public health, even though scientific evidence exists that demonstrates an impact on health. Expanding research on hydration is key; however, concrete actions like $\mathrm{EuH}$ $\mathrm{HAC}$ are needed to implement this knowledge into practice. Because barriers exist (Table 2), there is a need to create water-friendly environments to encourage healthier hydration behaviors. Providing education to dietitians about hydration science and giving them access to userfriendly tools is a first step. Future public actions are needed in every country.

\section{Statement of Ethics}

The authors have no ethical conflicts to disclose.
Belogianni/Gandy/van Ginkel/Liddell/ Wagner/Lagoudakis/Douglas 
Table 2. Dietitian perceptions regarding barriers and facilitators of fluid intake and methods to increase water intake in older people who reside in care homes

\begin{tabular}{|c|c|c|c|c|}
\hline \multirow[t]{2}{*}{ Questions } & \multicolumn{4}{|l|}{ Responses } \\
\hline & main themes & sub-themes & number of responses, $\%$ & dietitian responses \\
\hline \multirow[t]{6}{*}{$\begin{array}{l}\text { Describe barriers of } \\
\text { fluid intake in older } \\
\text { people residing at } \\
\text { care homes }(n=27)\end{array}$} & \multirow[t]{3}{*}{$\begin{array}{l}\text { 1. Barriers related to } \\
\text { older individuals }\end{array}$} & $\begin{array}{l}\text { 1.1 Aging-related } \\
\text { characteristics }\end{array}$ & $22(81.5)$ & $\begin{array}{l}\text { "Incontinence" } \\
\text { "Low thirst" } \\
\text { "Lack of motor ability to hold a cup, swallow, and so on." } \\
\text { "Low memory" }\end{array}$ \\
\hline & & $\begin{array}{l}\text { 1.2. Dietary or disease-related } \\
\text { characteristics }\end{array}$ & $2(7.4)$ & $\begin{array}{l}\text { "Low intake of salty foods due to other conditions" } \\
\text { "Increased medication- diuretics, low ADH" }\end{array}$ \\
\hline & & $\begin{array}{l}\text { 1.3. Personal (behavioural) } \\
\text { characteristics }\end{array}$ & $17(63.0)$ & $\begin{array}{l}\text { "Low literacy on how much to drink" } \\
\text { "Uncomfortable to use elderly diapers" } \\
\text { "Not asking for their preferred beverage" }\end{array}$ \\
\hline & \multirow[t]{3}{*}{$\begin{array}{l}\text { 2. Barriers related to human } \\
\text { resources/ facilities at care homes }\end{array}$} & 2.1 Resources & $5(18.5)$ & $\begin{array}{l}\text { "Time pressure of staff/ often times understaffed to ensure } \\
\text { hydration for every single patient" } \\
\text { "Availability of special beakers for safe swallowing (if not on } \\
\text { thickened fluids but bed-bound) to drink unassisted" }\end{array}$ \\
\hline & & $\begin{array}{l}\text { 2.2. Staff attitudes/ } \\
\text { behaviour }\end{array}$ & $7(25.9)$ & $\begin{array}{l}\text { "Not willing to remind patients to drink/ help them/ care" } \\
\text { "Lack of information/education" } \\
\text { "...serving drinks that they (older people) do not like" }\end{array}$ \\
\hline & & 2.3. Environment & $4(14.8)$ & $\begin{array}{l}\text { "Unavailability of good water sources" } \\
\text { "Toilet access" }\end{array}$ \\
\hline \multirow{6}{*}{$\begin{array}{l}\text { Describe facilitators } \\
\text { of fluid intake in older } \\
\text { people residing at } \\
\text { care homes }(n=26)\end{array}$} & \multirow[t]{3}{*}{$\begin{array}{l}\text { 1. Facilitators related to } \\
\text { individual characteristics }\end{array}$} & 1.1 Care givers & $6(23.1)$ & $\begin{array}{l}\text { "Carers can help" } \\
\text { "Family" }\end{array}$ \\
\hline & & $\begin{array}{l}\text { 2.2. Individual attitudes and } \\
\text { behaviour }\end{array}$ & $3(11.5)$ & $\begin{array}{l}\text { "Remember to take water with their medication" } \\
\text { "Education about benefits of hydration" }\end{array}$ \\
\hline & & $\begin{array}{l}\text { 2.3. Socializing/ interaction } \\
\text { with others }\end{array}$ & $6(23.1)$ & $\begin{array}{l}\text { "Find a way to link it to something fun" } \\
\text { "Having someone to have a drink with" }\end{array}$ \\
\hline & \multirow[t]{3}{*}{$\begin{array}{l}\text { 2. Facilitators related to human } \\
\text { resources/ facilities at care homes }\end{array}$} & $\begin{array}{l}\text { 2.1. Staff attitudes/ } \\
\text { behaviour }\end{array}$ & $13(50.0)$ & $\begin{array}{l}\text { "Ask people what drink you prefer" } \\
\text { "Give fluids with snack and medication" } \\
\text { "Keep good temperature of fluids when served" } \\
\text { "Encouraging to drink- helping with going to toilet } \\
\text { more often" } \\
\text { "Protected mealtimes" } \\
\text { "Staff that is aware of the importance" }\end{array}$ \\
\hline & & 2.2. Resources & $7(26.9)$ & $\begin{array}{l}\text { "Having willing staff available" } \\
\text { "Educate staff" } \\
\text { "Secure cups - for example, beakers/using straws" }\end{array}$ \\
\hline & & 2.3. Environment & $12(46.2)$ & $\begin{array}{l}\text { "Tap water coolers" } \\
\text { "Friendly design bathroom" } \\
\text { "Water access" }\end{array}$ \\
\hline \multirow[t]{2}{*}{$\begin{array}{l}\text { Record ideas to create } \\
\text { a water-friendly } \\
\text { enviroment and } \\
\text { encourage water intake } \\
\text { in community settings } \\
(n=23)\end{array}$} & \multicolumn{2}{|l|}{$\begin{array}{l}\text { 1. Actions that dietitians/health } \\
\text { professionals could take in practice }\end{array}$} & $16(69.6)$ & $\begin{array}{l}\text { "Keep patients record on intake- monitoring is key" } \\
\text { "Be a role model" } \\
\text { "Set fluid goals to work towards" } \\
\text { "Adapting in house dietsheets- adding in info fluid" } \\
\text { "Increase education regarding benefits" } \\
\text { "Make water fun/interesting" }\end{array}$ \\
\hline & $\begin{array}{l}\text { 2. Actions that community/policy } \\
\text { makers could take }\end{array}$ & & $17(73.9)$ & $\begin{array}{l}\text { "Clean water fountains strategically placed" } \\
\text { "Affordable water" } \\
\text { "Campaign (visual, video)" } \\
\text { "Public toilets" } \\
\text { "Education" } \\
\text { "Interesting bottle" } \\
\text { "Make it a social event ( } 5 \text { a day drink)" } \\
\text { "Awareness of nutritionists- community" }\end{array}$ \\
\hline
\end{tabular}




\section{Disclosure Statement}

R.Y.W. and L.L. are full time employees of Danone Research. J.G. is a member of the Fluid Intake Expert Group of Danone Research and has been employed as a consultant for Danone Research. K.B., J.G., A.G., J.L., and P.D. received travel expenses and registration fee from Danone Research to attend the 2018 Hydration for Health Scientific Conference.

\section{Author Contributions}

K.B. participated in the implementation of some project actions and prepared the manuscript. R.Y.W, L.L., J.G., and P.D. prepared and participated in the implementation of the actions of the project, reviewed the paper, and made critical comments to its content and structure. A.G. and J.L. contributed to the implementation of the overall project.

\section{References}

1 Popkin BM, D’Anci KE, Rosenberg IH. Water, hydration, and health. Nutr Rev. 2010 Aug;68(8):439-58

2 EFSA Panel on Dietetic Products, Nutrition, and Allergies. Scientific Opinion on Dietary Reference Values for water. EFSA J. 2010; 8(3): 1459

3 Martinez H, Guelinckx I, Salas-Salvadó J, Gandy J, Kavouras SA, Moreno LA. Harmonized Cross-Sectional Surveys Focused on Fluid Intake in Children, Adolescents and Adults: The Liq.In7 Initiative. Ann Nutr Metab. 2016;68 (Suppl 2):12-8.

4 Lotan Y, Daudon M, Bruyère F, Talaska G, Strippoli G, Johnson RJ, et al. Impact of fluid intake in the prevention of urinary system diseases: a brief review. Curr Opin Nephrol Hypertens. 2013 May;22(Suppl 1):S1-10.

5 Ferraro PM, Taylor EN, Gambaro G, Curhan GC. Dietary and Lifestyle Risk Factors Associated with Incident Kidney Stones in Men and Women. J Urol. 2017 Oct; 198(4):858-63.

6 Perrier E, Rondeau P, Poupin M, Le Bellego L, Armstrong LE, Lang F, et al. Relation between urinary hydration biomarkers and total fluid intake in healthy adults. Eur J Clin Nutr. 2013 09;67(9):939-43.

7 Armstrong LE. Assessing hydration status: the elusive gold standard. J Am Coll Nutr. 2007 Oct;26(5 Suppl):575S-84S.

8 Enhörning S, Wang TJ, Nilsson PM, Almgren P, Hedblad B, Berglund G, et al. Plasma copeptin and the risk of diabetes mellitus. Circulation. 2010 May 18;121(19):2102-8.

9 Enhörning S, Struck J, Wirfält E, Hedblad B, Morgenthaler NG, Melander O. Plasma copeptin, a unifying factor behind the metabolic syndrome. J Clin Endocrinol Metab. $2011 \mathrm{Jul}$; 96(7):E1065-72.

10 Enhörning S, Hedblad B, Nilsson PM, Engström G, Melander O. Copeptin is an independent predictor of diabetic heart disease and death. Am Heart J. 2015 Apr;169(4):549-56.e1.

11 Tasevska I, Enhörning S, Persson M, Nilsson PM, Melander O. Copeptin predicts coronary artery disease cardiovascular and total mortality. Heart. 2016 Jan;102(2):127-32.

12 El Boustany R, Tasevska I, Meijer E, Kieneker LM, Enhörning S, Lefèvre G, et al. Plasma copeptin and chronic kidney disease risk in 3 European cohorts from the general population. JCI Insight. 2018 Jul;3(13):121479.
13 Lemetais G, Melander O, Vecchio M, Bottin $\mathrm{JH}$, Enhörning S, Perrier ET. Effect of increased water intake on plasma copeptin in healthy adults. Eur J Nutr. 2018 Aug;57(5): 1883-90.

14 Enhörning S, Brunkwall L, Tasevska I, Ericson U, Tholin JP, Persson M, et al. Water supplementation reduces copeptin and plasma glucose in adults with high copeptin: the $\mathrm{H} 2 \mathrm{O}$ Metabolism pilot study. J Clin Endocrinol Metab. 2019 Jun;104(6):1917-25.

15 Hooton TM, Vecchio M, Iroz A, Tack I, Dornic Q, Seksek I, et al. Effect of Increased Daily Water Intake in Premenopausal Women With Recurrent Urinary Tract Infections: A Randomized Clinical Trial. JAMA Intern Med. 2018 Nov 1;178(11):1509-15.

16 Clark WF, Sontrop JM, Huang SH, Moist L, Bouby N, Bankir L. Hydration and Chronic Kidney Disease Progression: A Critical Review of the Evidence. Am J Nephrol. 2016; 43(4):281-92.

17 Gandy J, Le Bellego L, König J, Piekarz A, Tavoularis G, Tennant DR. Recording of fluid, beverage and water intakes at the population level in Europe. Br J Nutr. 2016 Aug 28; 116(4):677-682.

18 Guelinckx I, Tavoularis G, König J, Morin C, Gharbi H, Gandy J. Contribution of Water from Food and Fluids to Total Water Intake: Analysis of a French and UK Population Surveys. Nutrients. 2016 Oct;8(10):E630.

19 Nissensohn M, Fuentes Lugo D, Serra-Majem L. Comparison of beverage consumption in adult populations from three different countries: do the international reference values allow establishing the adequacy of water and beverage intakes? Nutr Hosp. 2016 Jul; 33(Suppl 3):313-313.

20 Bleich SN, Vercammen KA. The negative impact of sugar-sweetened beverages on children's health: an update of the literature. BMC Obes. 2018 Feb;5(5):6-6.

21 Bernabé E, Vehkalahti MM, Sheiham A, Aromaa A, Suominen AL. Sugar-sweetened beverages and dental caries in adults: a 4-year prospective study. J Dent. 2014 Aug;42(8):952-8.

22 World Health Organization. Guideline: Sugars intake for adults and children. WHO; 2015.

23 Gazan R, Sondey J, Maillot M, Guelinckx I, Lluch A. Drinking Water Intake Is Associated with Higher Diet Quality among French Adults. Nutrients. 2016 Oct 31;8(11). pii: E689.

24 Luger M, Lafontan M, Bes-Rastrollo M, Winzer E, Yumuk V, Farpour-Lambert N. SugarSweetened Beverages and Weight Gain in Children and Adults: A Systematic Review from 2013 to 2015 and a Comparison with Previous Studies. Obes Facts. 2017;10(6): 674-93.

25 Stookey JD. Under What Conditions do Water-Intervention Studies Significantly Improve Child Body Weight? Ann Nutr Metab. 2017;70(Suppl 1):62-7.

26 Gandy J. Water intake: validity of population assessment and recommendations. Eur J Nutr. 2015 Jun;54(Suppl 2):11-6.

27 Bardosono S, Monrozier R, Permadhi I, Manikam NR, Pohan R, Guelinckx I. Total fluid intake assessed with a 7-day fluid record versus a 24-h dietary recall: a crossover study in Indonesian adolescents and adults. Eur J Nutr. 2015 Jun;54(Suppl 2):17-25.

28 Johnson EC, Péronnet F, Jansen LT, CapitanJiménez C, Adams JD, Guelinckx I, et al. Validation Testing Demonstrates Efficacy of a 7-Day Fluid Record to Estimate Daily Water Intake in Adult Men and Women When Compared with Total Body Water Turnover Measurement. J Nutr. 2017 Oct;147(10): 2001-7.

29 Warren J, Guelinckx I, Livingstone B, Potischman N, Nelson M, Foster E, et al. Challenges in the assessment of total fluid intake in children and adolescents: a discussion paper. Eur J Nutr. 2018 Jun;57(Suppl 3):43-51.

30 Jimoh FO, Bunn D, Hooper L. Assessment of a Self-Reported Drinks Diary for the Estimation of Drinks Intake by Care Home Residents: Fluid Intake Study in the Elderly (FISE). J Nutr Health Aging. 2015 May; 19(5): 491-6.

31 Reid J, Robb E, Stone D, Bowen P, Baker R, Irving $\mathrm{S}$, et al. Improving the monitoring and assessment of fluid balance. Nurs Times. 2004 May 18;100(20):36-9.

32 Monnerie B, Tavoularis LG, Guelinckx I, Hebel P, Boisvieux T, Cousin A, et al. A cross-over study comparing an online versus a paper 7-day food record: focus on total water intake data and participant's perception of the records. Eur J Nutr. 2015 Jun;54(Suppl 2):27-34. 
33 Douglas P, Ball L, Mcguffin L, Laur C, Crowley J, Minha Rajput-Ray, et al. Hydration: Knowledge, Attitudes, and Practices of UK Dietitians. Journal of Biomedical Education 2015:172020.

34 World Health Organization. WHO European Action Plan for Food and Nutrition Policy 2015-2020. Global Action Plan for the prevention and control of noncommunicable diseases 2013-2020. 2014 [Accessed 24 April 2019]. Available from: http://www.euro.who.int/ data/assets/pdf_file/0008/253727/64wd14e_ FoodNutAP_140426.pdf?ua=1.
35 European Federation of the Associations of Dietitians. European Dietetic Action Plan. EuDAP (2015-2020). 2015 [Accessed 24 April 2019]. Available from: http://www.efad. org/media/1176/eudap-2016-report-executive-summary.pdf.

36 Eller LS, Kleber E, Wang SL. Research knowledge, attitudes and practices of health professionals. Nurs Outlook. 2003 Jul-Aug;51(4): $165-70$.
37 Vogt K, Johnson F, Fraser V, Koh JC, McQueen K, Thornhill J, et al. An Innovative, Strengths-Based, Peer Mentoring Approach to Professional Development for Registered Dietitians. Can J Diet Pract Res. 2015 Dec; 76(4):185-9.

38 Sinclair P, Kable A, Levett-Jones T. The effectiveness of internet-based e-learning on clinician behavior and patient outcomes: a systematic review protocol. JBI Database System Rev Implement Rep. 2015 Jan;13(1):5264. 